\title{
Design e Artesanato: uma relação social recíproca
}

\author{
Design and Craft: a reciprocal social relationship
}

LORENZI, Rita de Cássia Rothbarth; Msc; UNIVILLE

rita.lorenzi@gmail.com

MORGENSTERN, Elenir Carmen; Dra; UNIVILLE

elenir.m@gmail.com

\section{Resumo}

O artigo apresenta os principais resultados da pesquisa de Mestrado Profissional em Design, desenvolvida junto a Universidade da Região de Joinville. O estudo aborda a temática 'Design de Moda, produção manual e identidade cultural'. A metodologia desdobra-se com base teorética na abordagem social e investe na aplicação da teoria na prática de projetos, de extensão universitária, que capacitam mulheres em estado de vulnerabilidade social. A investigação destaca a responsabilidade social e a necessidade de uma relação social recíproca, entre artesãos e designers, na busca de identidade para os artefatos produzidos, considerando-se os agentes produtores e o local histórico/geográfico/cultural dessa produção. Os principais resultados referem-se à apresentação de diretrizes norteadoras para as práticas produtivas dos projetos de extensão e apresentação de proposições metodológicas que considerem aspectos extra-estéticos nos processos produtivos.

Palavras Chave: Design de Moda; Artesanato; Projetos de geração de trabalho e renda.

\begin{abstract}
The article presents the main results of the Master's Degree in Design, developed at the University of the Region of Joinville. The study addresses the theme 'Fashion Design, Manual Production and Cultural Identity'. The methodology unfolds with theoretical basis in the social approach and invests in the application of the theory in the practice of projects, of university extension, that enable women in a state of social vulnerability. The research highlights social responsibility and the need for a reciprocal social relationship between artisans and designers, in the search for identity for the artifacts produced, considering the producing agents and the historical / geographic / cultural location of this production. The main results refer to the presentation of guiding guidelines for the productive practices of extension projects and presentation of methodological propositions that consider extra-aesthetic aspects in the productive processes.
\end{abstract}

Keywords: Fashion design; Crafts; Work and income generation projects. 


\section{Introdução}

Experiências desenvolvidas por professores de design, numa universidade comunitária catarinense ${ }^{1}$, em projetos de extensão universitária que capacitam para a geração de trabalho e renda, por meio de saberes oriundos do campo do design, destacaram uma problemática em especial: mulheres artesãs, capacitadas em projetos sociais, passam a adotar procedimentos, sob a orientação de professores de design, e incorporam, em suas produções, modos produtivos pautados em metodologia do campo do design; materiais nativos e técnicas familiares e locais, paulatinamente, podem ser abandonados. Em decorrência disso, os artefatos produzidos descaracterizam o grupo que os produz e não integram materiais locais, desconsiderando o meio ambiente. Essa problemática deu luz à reflexão de mestrado intitulada "Design de Moda e Artesanato: uma relação social recíproca", que propõe, de modo integrado aos saberes específicos do campo do design, um retorno às características locais, em busca de uma produção manual que reflita as condições materiais locais e a identidade cultural dos agentes produtores. Propôs-se, a partir desta investigação, a verificação de contribuições dos estudos fundados na abordagem social, para o campo do Design de Moda, com vistas a sua aplicabilidade a projetos que visam à geração de trabalho e renda por meio de processos artesanais. Entendendo que as produções de tais grupos são situadas geográfica e historicamente, intencionou-se fomentar o desenvolvimento de novos artefatos, integrando-se ferramentas e tecnologias acadêmicas do campo do Design de Moda com os conhecimentos populares de técnicas, processos e materiais locais, compreendendo, em tais práticas, a relevância de estabelecer uma relação social recíproca.

\section{Contextualizando o campo de estudo}

O objetivo da investigação foi verificar a contribuição dos estudos fundados na abordagem social para o campo do Design de Moda, visando aplicabilidade a projetos que propõem geração de renda por meio de processos artesanais.

A metodologia apoiou-se na Teoria dos Sistemas Simbólicos, de Pierre Bourdieu. Para Bourdieu2 $^{2}$, não basta analisar o objeto de estudo isoladamente, é necessário sopesar o campo no qual está inserido e considerar o sistema simbólico nele instituído. A questão central desta investigação foi buscar respostas sociológicas - ou seja, lógicas e ao mesmo tempo empíricas. 0 viés sociológico, elegido para a investigação, conduziu ao entendimento de que os agentes envolvidos no processo analisado têm sua responsabilidade, mas são em grande parte definidos em suas possibilidades ou impossibilidades, pela estrutura na qual estão situados e pela posição que ocupam nessa estrutura. Não se compreende nada se não se compreende o campo que o produz e que lhe confere pequena força.

A Teoria dos Campos, em Bourdieu, refere-se às questões de legitimação, decorrentes de padrões culturais, dos campos simbólicos. O campo é o espaço social (simbólico) de conflito onde as relações sociais (efetivadas pelos agentes e por classes de agentes) estão distribuídas na forma de capital, seja simbólico ou cultural, e por meio das quais se estabelecem as relações de

\footnotetext{
${ }^{1}$ A Fundação Educacional da Região de Joinville - FURJ - é uma entidade de direito privado, sem fins lucrativos, com autonomia didático-científica, administrativa, financeira e disciplinar, exercida na forma da lei e dos seus estatutos, mantenedora da Universidade da Região de Joinville - Univille.

2 BOURDIEU, Pierre. 2003.

${ }^{3}$ BOURDIEU, Pierre. 2003, p. 65.
} 
dominação. O campo é articulado pelas lutas, disputas pelo poder, entre os agentes, sempre dispostos a envolverem-se, com o objetivo de demarcarem suas posições na estrutura social (distinção). Por maior que seja a autonomia do campo, o resultado dessas lutas nunca é completamente independente de fatores externos. Em outros termos, as relações de força (entre o velho e o novo) dependem do estado das lutas externas e do reforço que uns e outros possam encontrar fora do campo. ${ }^{4}$

\subsection{Agentes produtores}

Para Bourdieu, o agente é o ser que participa e pleiteia dentro do campo de interesses. 0 autor esclarece que os agentes obtêm o capital econômico e cultural de acordo com sua origem social, determinantes desde o seu nascimento. Ao transcorrer do tempo os agentes assimilam formas de agir dentro do meio social.

Conforme dados coletados e arquivados pelos projetos 'SempreViva' e 'Vida em Flor', projetos elegidos para a aplicação prática da pesquisa, os agentes aqui referidos são mulheres de baixa escolaridade ( $70 \%$ possuem o ensino fundamental) e renda ( $45 \% \mathrm{com}$ ganho de até $\mathrm{R} \$ 724,00)$, cadastradas na Secretaria de Assistência Social (Programa de Incentivo às Organizações Produtivas), que almejam, ao ingressar nos projetos de geração de renda da UNIVILLE, se qualificar para o mercado de trabalho, com vistas ao complemento da renda familiar. Tratam-se de donas de casa casadas (50\%), separadas ou divorciadas (30\%), procedentes de cidades do interior de Santa Catarina e Paraná, que se dedicam aos afazeres domésticos e à educação dos filhos (em média 3). Moradoras da periferia de Joinville, dominam determinadas técnicas artesanais, como crochê, bordado, fuxico ou patchwork. Algumas das integrantes vêm em busca de atividade que alivie a rotina doméstica, outras foram diagnosticadas com quadro de depressão. Com a capacitação nos projetos passam a integrar o mercado de trabalho por meio de atividade empreendedora, autônoma ou vinculada a uma associação. As agentes produtoras ao se cadastrarem na Secretaria de Assistência Social, passam a integrar os projetos de capacitação para a geração de trabalho e renda SempreViva, Vida em Flor ou 'AmaViva', desenvolvidos na UNIVILLE. Entre os agentes envolvidos estão professores e estudantes do curso de Design (principalmente da linha de formação em Moda).

\section{Considerando os sistemas simbólicos}

De acordo com Bourdieu, a ciência deve aplicar aos campos de estudo o princípio da teoria do conhecimento antropológico, segundo o qual os sistemas simbólicos que um grupo produz e reproduz no âmbito de um tipo determinado de relações sociais adquirem seu verdadeiro sentido quando referidos às relações de força que os tornam possíveis e socialmente necessários. ${ }^{5}$ Seguindo essa diretriz, é preciso evidenciar que os gostos (legitimados ou institucionalizados como tal) e as preferências estilísticas pelos artefatos produzidos e comercializados, não são apenas um reflexo da estrutura social, como também um meio de afirmação e de adequação a uma vinculação social. ${ }^{6}$

\footnotetext{
${ }^{4}$ Idem.

${ }^{5}$ BOURDIEU, 2007. p. 176.

${ }^{6}$ CIPINIUK, 2014. p. 83.
} 


\subsection{Artesanato, moda e identidade}

Pode-se dizer que o sentimento de nostalgia encontra, no artesanato, a lembrança de momentos vividos associada a um desejo de regresso, impulsionado por lembranças e antigas relações sociais. A noção que se tem no momento atual (já que as práticas artesanais das sociedades, que antes eram essenciais, foram substituídas quase que totalmente pelas industriais) é a de que quem produz, distribui ou compra produtos artesanais promove uma tradição de tempos antigos.

Para Cipiniuk ${ }^{7}$, faz-se necessário definir claramente o tipo de cultura que acarreta o artesanato e, sobretudo, não deixar de considerar que o povo que o produz participa do sistema integrado de comunicação dos mesmos valores, ouvem rádio e assistem televisão e, o mais importante, em sua maioria residem nas periferias e, mesmo morando longe, nas áreas antes denominadas rurais, têm íntimo contato com centros urbanos, ou seja, estão dentro do sistema capitalista. No entender de Cipiniuk, o artesanato deve ser pensado juntamente com outro tipo de produção do mesmo sistema de produção, e não algo contrário a ele ${ }^{8}$. 0 diálogo entre design e artesanato passa pelo respeito a um tipo de cultura desprezada; trata-se de integrar as classes sociais e as suas diferentes culturas a um sistema que as separa ${ }^{9}$.

\subsection{Identidade/hibridismo cultural}

Compreendeu-se, na investigação ora relatada, que é necessário, quando se almeja uma produção cultural híbrida, envolvendo design e artesanato, considerar o contexto em meio ao qual as práticas são desenvolvidas. Entendeu-se ainda a relevância de levar-se em conta que a cultura local é constituída pelo empréstimo cultural de outras culturas ${ }^{10}$. Nesse ponto, entra-se em concordância com Canclini ${ }^{11}$, em sua afirmação de que hoje todas as culturas são de fronteira.

Entretanto é relevante um posicionamento teórico no tocante ao entendimento do fenômeno (por alguns teóricos denominado hibridismo cultural - atacado por uns e defendido por outros - e por outros chamado com outros termos), evidenciando que, no encalço dos escritos de Burke $^{12}$, entendemos que as formas híbridas de hoje não são necessariamente um estágio no caminho para uma cultura global homogênea ou para uma desintegração cultural. Para Burke, a análise mais convincente de nossa cultura é aquela que vê uma nova ordem, surgindo uma formação de novos ecotipos, a cristalização de novas formas, a reconfiguração de culturas, a "crioulização do mundo"13. Buscando-se uma resposta sociológica ao problema, apresentado nesta investigação, entende-se que seja fundamental confrontar as teorias com a prática dos grupos de geração de renda.

No caso de Joinville/SC, o hibridismo cultural é facilmente percebido, já que a cidade se constitui, em grande parte, por pessoas provenientes de outras localidades. Esse fator é intensificado pela característica industrial e universitária da cidade, que atrai trabalhadores de diferentes Estados do Brasil. A própria constituição dos grupos que integram os projetos de

\footnotetext{
${ }^{7}$ CIPINIUK. Design e artesanato: aproximações, métodos e justificativas. Artigo apresentado no 70 P\&D, 2006.

${ }^{8}$ Id. Ibid.

${ }^{9}$ Id. Ibid.

${ }^{10}$ SAID, Edward. in BURKE, Peter. Hibridismo cultural. 2003, p.13.

${ }^{11}$ CANCLINI, Nestor G. in BURKE, Peter. Hibridismo cultural. 2003, p.13.

12 BURKE, Peter. Hibridismo cultural. 2003, p.116.

13 Idem.
} 
geração de renda da UNIVILLE evidencia o caráter multicultural. Observa-se a necessidade de considerar tal hibridação na definição da identidade cultural do grupo de artesãs dos projetos. Dessa forma, a intenção não é cristalizar uma cultura formulada no passado, nem tampouco entendê-la como uma fragmentação, num fenômeno mundial, mas sim observar o momento histórico, considerar as necessidades socioambientais, absorver os conhecimentos do passado cultural e estabelecer uma relação social recíproca entre os saberes compostos pela tradição das artesãs e os saberes atuais de ferramentas e métodos do Design.

Em meio a esse arcabouço de ideias, vale reforçar a perspectiva da investigação aqui apresentada: entendeu-se que as culturas não permanecem puras; nem tampouco é possível separar taxativamente o Design do artesanato. Se continua havendo artesanato, ainda que seja reformulado pelas indústrias culturais, é porque ainda funciona como núcleo simbólico para expressar formas de produção e representação ${ }^{14}$. Da mesma forma, impossível negar a intercessão entre os métodos do Design e as práticas artesanais. Compreende-se que, como aponta Canclini, é possível construir uma nova perspectiva de análise do tradicional-popular levando em conta suas interações com a cultura de elite e com as indústrias culturais. ${ }^{15}$

\subsection{Moda e sociedade}

Bourdieu ${ }^{16}$ considera que certas maneiras de tratar as roupas e os enfeites, aqui transpostos para a terminologia Design de Moda, exprimem, de forma simbólica, fatores de distinção, no meio social. De acordo com Bourdieu, entre todos os tipos de consumo e de conduta passíveis de abrigar uma função expressiva, quer se trate da compra de um automóvel, da decoração de um apartamento ou da escolha de uma escola para os filhos, são as roupas e os enfeites (em virtude de seu elevado rendimento simbólico) que, ao lado, da linguagem e da cultura, melhor realizam a função de socialização e dissociação. ${ }^{17}$

O poder simbólico, conforme Bourdieu ${ }^{18}$, imperceptível e invisível, é uma forma transfigurada e legitimada das outras formas de poder. E o que torna possível tal poder é a cumplicidade daqueles que não querem saber que lhe estão sujeitos ou mesmo que o exercem, conclui o autor. Para o mencionado autor, a conversão do capital econômico em capital simbólico, mediante o desperdício de energia social que é a condição da permanência da dominação, só pode ter sucesso com a cumplicidade de todo o grupo. No entender do teórico, o trabalho de denegação que está na origem da alquimia social é, como a magia, um empreendimento coletivo. ${ }^{19}$

O termo habitus, adotado por Bourdieu ${ }^{20}$ para estabelecer a diferença entre conceitos correntes como hábito, costume, praxe, tradição, situa-se entre a estruturação e a ação. "Denota o sistema de disposições duráveis e transferíveis, que funciona como princípio gerador e organizador de práticas e de representações, associado a uma classe particular de condição de existência"21. Ele funciona como um esquema de ação, percepção e reflexão. "Presente no corpo

\footnotetext{
${ }^{14}$ CANCLINI, Nestor Garcia. Culturas Híbridas. 2013, p. 364.

${ }^{15}$ CANCLINI, Nestor Garcia. Culturas Híbridas. 2013, p. 214-215.

${ }^{16}$ BOURDIEU, 2011. p. 18.

17 Id. Ibid.

${ }^{18}$ BOURDIEU, 2002. p. 10 - 15.

${ }^{19}$ BOURDIEU, 2006.

${ }^{20}$ THIRY-CHERQUES. Artigo do professor da FGV que discute o sistema de conceitos que Bourdieu utiliza. 2006, p. 33.

${ }^{21}$ Id. Ibid.
} 
(gestos, posturas) e na mente (formas de ver, de classificar) da coletividade inscrita em um campo, automatiza as escolhas e as ações em um campo dado, 'economiza' o cálculo e a reflexão". 22 Trata-se do produto da experiência biográfica individual, da experiência histórica coletiva e da interação entre essas experiências. E contém as potencialidades objetivas, associadas à trajetória da existência social dos indivíduos, que tendem a se atualizar, ou seja, são reversíveis e podem ser aprendidas. ${ }^{23}$

É interessante considerar o Design de Moda com base nas noções de campo e habitus de Bourdieu. De fator isolado, o Design de Moda passa a ser compreendido a partir de sua relação com os agentes produtores e consumidores. Estes são contemplados pela consideração do gosto vigente, moldado pelo habitus instituído socialmente. Reiterando os posicionamentos dos teóricos antes citados ${ }^{24}$, entende-se, nesta investigação, que o Design de Moda atua na sociedade como fator de distinção, por meio do valor simbólico atribuído aos artefatos, aos designers ou às marcas que representa.

\subsection{Limites e hibridismos no campo da moda}

Como referência fundamental acerca da temática, destaca-se o entendimento de Canclini ${ }^{25}$ sobre noção de cultura híbrida. $\mathrm{O}$ autor observa que os fenômenos culturais folclóricos ou tradicionais são o produto multideterminado de agentes populares e hegemônicos, rurais e urbanos, locais, nacionais e transnacionais. Por extensão, de acordo com o referido teórico, é possível pensar que o popular é constituído por processos híbridos e complexos, usando como signos de identificação de elementos procedentes de diversas classes e nações.

A moda, ao pensar-se em possibilidades híbridas, apropria-se dos mais variados elementos culturais e sociais para criar tendências e lançar novos produtos no mercado. Logo, a moda também se apropria de elementos populares, como o artesanato, que pode estar presente de diversas formas, seja nos acessórios, na customização de peças, bordados e aplicações. ${ }^{26}$

O Design de Moda, desse modo, constitui-se a partir de elementos culturais e sociais. Nesses moldes, torna-se importante considerar as características territoriais, incluindo, nos projetos, as possibilidades técnicas tradicionais e os recursos naturais da região.

\subsection{Identidade cultural e responsabilidade socioambiental}

O desenvolvimento sustentável abrange, além da evolução no processo de produção, um novo estilo de vida: o de um consumidor ativo, engajado nos problemas da humanidade, preocupado com valores éticos e que procura, por meio de seus atos e compras, trazer o consumo consciente para sua vida. ${ }^{27}$ Num processo de socialização, no qual as pessoas passam a desenvolver seus valores e atividades, as práticas adotadas pelos consumidores dentro da família, nas instituições de ensino e suas experiências de vida formatam essa nova postura de consumo, que caracteriza a sociedade futura. Seus valores essenciais influenciam suas escolhas de

\footnotetext{
${ }^{22}$ THIRY-CHERQUES, 2006, p. 34.

23 Id. Ibid.

${ }^{24}$ SCARTEZINI, s.d.; THIRY-CHERQUES, 2006; MORGENSTERN, 2011. Sobre a metodologia de pesquisa utilizada por Pierre Bourdieu.

${ }^{25}$ CANCLINI, 2011, p. 220.

${ }^{26}$ LINKE; VELHO. Revista Multidisciplinar da UNIESP, 2014.

27 Id. Ibid.
} 
consumo. ${ }^{28}$

Mostra-se fundamental para a manutenção da cultura dos agentes produtores que se valorize a matéria-prima local. É essencial, para a manutenção dos processos naturais do planeta, que se considere o meio ambiente no momento de escolha das matérias-primas, as quais devem ser renováveis, de acordo com as condições climáticas e geográficas do local em que ocorre a produção.

\subsection{Joinville: produção cultural e mercado}

Para Bourdieu, a distinção aponta para um exame social do "julgamento do gosto", destacando a existência de uma economia de bens culturais. As escolhas do ser humano são "distinções" interligando interesses de classes de agentes e configurando-se em escolhas feitas em oposição àquelas praticadas por pessoas de outras classes ${ }^{29}$.

Os habitus estabelecem as diferenças nas práticas dos agentes, ou de seus grupos, em meio ao campo ${ }^{30}$. Essas diferenças são constitutivas de sistemas simbólicos, configurando-se em signos distintivos, propiciando o estabelecimento de diferenciadas categorias de percepção ${ }^{31}$.

O município de Joinville, fundado em 9 de março de $1851^{32}$, demonstrou um processo de desenvolvimento diferenciado em relação a outras regiões do Brasil, que recebiam imigrantes europeus, notadamente alemães, em meados do século XIX. Enquanto os imigrantes enviados para São Paulo trabalharam em regime de semi servidão nas lavouras de café, os que se dirigiram para a Colônia Dona Francisca (atual Joinville) adquiriram lotes de terra, proporcionando-lhes determinada autonomia para desenvolver suas atividades, decorrendo o rápido aparecimento de núcleos urbanos ${ }^{33}$.

A professora Dra. Janine Gomes da Silva ${ }^{34}$ observa que a migração masculina foi direcionada para a lavoura ou para a abertura de estradas. Restou às mulheres e aos filhos a responsabilidade da lida diária. Além de esposas, mães e donas de casa, as mulheres foram também colonas, costureiras, cozinheiras, parteiras, professoras e proprietárias de estabelecimentos comerciais. Quando professoras, as mulheres geralmente ensinavam trabalhos manuais, "tendo em vista que as atividades relacionadas à educação das meninas deveriam estar voltadas para o interior - o lar"35.

Pequenas peculiaridades foram transmitidas através das gerações, conforme a pesquisa antropológica ao Museu de Imigração e Colonização de Joinville. Uma dessas especificidades é o bordado "familiar". Aprendido em casa pelas moças, servia para registrar em tecidos passagens importantes, como nascimento de uma criança ou casamento dos cônjuges, usado como quadro ou porta-retrato memorial. Atualmente, ainda se reúnem em Joinville grupos de idosos que

\footnotetext{
${ }^{28} \mathrm{RECH}$; SOUZA. web, 2014

${ }^{29}$ BOURDIEU, 2008.

${ }^{30}$ BOURDIEU, 2003, p. 21.

${ }^{31}$ Id. Ibid. p. 22.

32 É recorrente encontrarmos nos escritos uma íntima relação com os fatos que registram o início da colonização, não levando em consideração os povos sambaquianos, indígenas e nem mesmo os brasileiros que se encontravam nas proximidades. "Há uma espécie de mito fundador que valoriza os registros da época, acerca dos primeiros imigrantes e seu pioneirismo, contando e recontando a história a partir de 1851" (SILVA, 2004, p. 22).

${ }^{33}$ VEGINI, 2004. p. 119.

${ }^{34}$ SILVA, 2004. p. 26.

35 Id idem. p. 98.
} 
dominam as técnicas manuais, passadas de geração em geração, especialmente o bordado e o tricô. Além de praticarem o trabalho manual, exercitam a conversação alemã, recheada de dialetos e termos antigos ainda perpetuados entre os antigos e também entre as novas gerações, que estão se interessando, ainda timidamente, pelo passado da cidade e pelas suas tradições. ${ }^{36}$

Pode-se apontar como aspecto fundamental para o sucesso do empreendedorismo colonizador a vinda de três tipos de imigrantes: o colonizador que se fixou na estrada Dona Francisca; o imigrante artífice que caracterizou a propensão industrial e o imigrante intelectual que garantiu os fundamentos para o processo de desenvolvimento da Colônia, referindo-se à organização político-administrativa e cultural ${ }^{37}$.

Em 30 anos, a partir da segunda metade do século 19, mais de 17 mil imigrantes europeus estabeleceram-se na Colônia, entre alemães, suíços, franceses, austríacos e, principalmente, italianos. Justamente nesse período surgiram as primeiras indústrias metalúrgicas e têxteis da região ${ }^{38}$.

Conforme Censo IBGE realizado em 2010, a taxa média de crescimento populacional anual da cidade foi de $1,69 \%$, acima da média nacional (1,17\%) e estadual (1,55\%). Cerca de $60 \%$ da população que mora em Joinville tem entre 18 e 59 anos (49,63\% de homens e 50,36\% de mulheres). As famílias joinvilense são formadas, em média, por 3 ou 4 pessoas, e aproximadamente $70 \%$ da população (per capita) urbana recebe até 3 salários mínimos por mês.

Dos moradores da cidade, $46 \%$ da população completou o ensino fundamental e aproximadamente $10 \%$ não completou o ensino médio. Reforçando-se a baixa escolaridade, um dos quesitos para que os trabalhadores formais recebam até 3 salários mínimos por mês.

No espaço social, Joinville experimenta intenso processo de crescimento populacional, relacionado à contínua migração de grandes contingentes populacionais oriundos, especialmente, do oeste paranaense em busca de trabalho ${ }^{39}$.

Gonçalves e Oliveira complementam afirmando que os atrativos naturais de Joinville são de excepcional beleza e extremamente diversificada, podendo-se escolher entre a Baía da Babitonga ${ }^{40}$, com o canal do Palmital com seus mangues, e a Serra do Mar com as cachoeiras que despencam das encostas, com altitudes médias de 900 metros e paredões de rocha, como o Castelo dos Bugres, Pelado e o Jurapê, além dos campos de altitude e florestas de araucária, num trecho de menos de 30 quilômetros em linha reta ${ }^{41}$.

Joinville recebeu diversos títulos ao longo das décadas de 1940, 60 e 8042, tornando-se conhecida como "Cidade dos Príncipes", "Manchester Catarinense" 43, "Cidade das Bicicletas", "Cidade das Flores" e "Cidade da Dança".

Evidenciam-se a rica história da imigração de Joinville e a herança cultural que os imigrantes trouxeram, marcada pelo hibridismo cultural. Percebem-se, ainda hoje, pequenas

\footnotetext{
${ }^{36}$ SOUZA. Pesquisa de Iniciação Científica PIBIC/CNPQ. O design de Moda e a instituição social da cultura simbólica. 2014.

${ }^{37}$ VEGINI, 2004, p. 119.

38 Id. Ibid.

${ }^{39}$ VEGINI, 2004, p. 121.

${ }^{40}$ A Baía da Babitonga compreende os municípios de Joinville, Araquari, Balneário Barra do Sul, Garuva, Itapoá e São Francisco do Sul.

41 Joinville: 150 anos. Gonçalves; Oliveira. O meio ambiente e a sua dinâmica na região de Joinville, 2001. p. 73.

${ }^{42}$ Guiaville. Durante o ano inteiro Joinville oferece uma extensa programação cultural. web, 2014.

43 É uma cidade do Reino Unido, no noroeste da Inglaterra. A cidade é um grande centro industrial e econômico. Disponível em: <http://www.dicionarioinformal.com.br/manchester/>. Manchester. web, 2014.
} 
peculiaridades gastronômicas - com pratos genuinamente joinvilense - e artesanais com peças bordadas manualmente.

Ressalta-se o intenso processo de crescimento populacional referente à contínua migração de pessoas em busca de trabalho. Dos moradores, apenas $46 \%$ da população completou o ensino fundamental e aproximadamente $10 \%$ não completou o ensino médio.

Considerando-se os dados coletados sobre Joinville e levando em conta as bases teóricas de Bourdieu, práticas diferenciadas focadas na capacitação para o trabalho, foram realizadas oficinas com as integrantes dos projetos Vida em Flor e SempreViva, resultando no desenvolvimento e confecção de artefatos funcionais, como apresentado no próximo capitulo.

\section{Aplicando a teoria na prática}

A investigação destacou a relevância de estabelecer uma relação social recíproca entre Design e artesanato. Não vislumbrou dois segmentos opositores nem tampouco entendeu que o desenvolvimento moderno, com a evolução do saber culto do Design, tenha suprimido ou venha a suprimir as culturas populares tradicionais.

Por essa perspectiva, concebendo os saberes cultos do Design e os saberes populares do artesanato, em meio a uma relação social recíproca, marcada pelo hibridismo cultural, e tendo como pano de fundo a Teoria dos Sistemas Simbólicos, desenvolvida por Pierre Bourdieu, propôsse, uma análise das práticas dos grupos integrantes dos projetos que visam à geração de trabalho e renda desenvolvidos pela Extensão Universitária da UNIVILLE. Na abordagem prática, os referenciais teóricos foram confrontados com a pesquisa prática, sistemática, que objetivou romper com o senso comum ao estabelecer relações do objeto estudado com fatores externos (históricos, sociais, culturais, filosóficos, econômicos). Em suma, propôs-se um senso prático. Tratou-se de uma tentativa de avaliar o mundo prático que se constitui na relação com o habitus, enquanto sistema de estruturas cognitivas e motivadoras. ${ }^{44}$

A pesquisa prática foi realizada em dois grupos específicos: Projeto Geração de Renda Vida em Flor e Geração de Renda: Grupo SempreViva ${ }^{45}$. Os referidos grupos reúnem-se semanalmente nas dependências da UNIVILLE, com carga de quatro horas semanais, sendo orientados por professores dos cursos de Design (Moda, Produto, Gráfico) e Administração e apoiados por estudantes bolsistas e voluntários.

\subsection{Como ficaram as oficinas a partir das reflexões teóricas}

As oficinas, ao longo dos 7 anos de experiência dos projetos de geração de renda da UNIVILLE, eram planejadas conforme tópicos definidos pelos professores. Os assuntos abordados em sala ofereciam temas predefinidos, com aula expositiva e prática, conforme programação efetuada pelo docente responsável pela disciplina. Não havia conexão entre os conteúdos nem tampouco troca de informações acerca do teor das abordagens nas oficinas. Em certos casos, o bolsista do projeto deveria procurar o professor para entender o assunto tratado. Os materiais utilizados eram adquiridos pelo projeto, não havendo preocupação com questões ambientais ou sustentabilidade. A estampa das peças foram serigrafadas, conforme o tema proposto, de maneira seriada, sem a preocupação de customizá-las. Assim, como resultado, produziram mais um

\footnotetext{
44 BOURDIEU, 2013, p.88.

${ }^{45}$ Grupos apresentados e contextualizados como 2.1 Agentes produtores.
} 
acessório temático, entre tantos existentes no mercado.

A partir das reflexões teóricas do presente projeto de pesquisa, as integrantes dos projetos passaram a participar do planejamento, contribuindo com suas ideias. O professor responsável começou a ouvir e enxergar, de maneira a instigar novas possibilidades de utilização dos conhecimentos e vivência relatados pelas participantes.

\subsubsection{Desdobramentos e resultados junto ao Projeto SempreViva}

Nessa turma, conforme levantamento, significativo percentual veio de outras cidades. Algumas nasceram em Joinville e outras vieram de cidades desenvolvidas do interior de Santa Catarina. Assim, foram apontadas, em sala, as principais características conhecidas pelas integrantes sobre a cidade que escolheram para morar: uma cidade tranquila, hospitaleira e com oportunidades de empregos e estudo. A principal característica observada na oficina de linguagem visual foi a vegetação presente em Joinville, visto que a maioria mora em residências com espaço para quintais e hortas.

Pela pesquisa feita, confere-se o carinho com que são cuidadas as residências das integrantes. Trata-se de uma característica reconhecida pelo cuidado das ruas e jardins (público ou privado) de Joinville. Com espaço para quintais, as residências das integrantes são providas de diversas plantas. Assim, diferentes plantas, árvores e flores foram citadas. Muitos comentários e histórias puderam ser trocados, assim como receitas de chás e sobre mudas das plantas.

$\mathrm{Na}$ oficina de linguagem visual, puderam conhecer diferenciados tipos de texturas, formas e cores característicos dos elementos visuais a serem empregados na proposta do produto. Ainda, tonalidades terrosas e cores como amarelo, vermelho, roxo e verde foram encontradas, seguidas das formas orgânicas das sementes, como abacate e abóbora.

Posteriormente, puderam reconhecer e desenhar as formas das espécies trazidas para sala de aula. Depois foram feitas fotocópias para escolha e análise dos vegetais, logo em seguida puderam desenhar o formato dos galhos, folhas e flores. Observou-se preferência, por parte das integrantes, pelas flores das plantas trazidas.

Em seguida, as técnicas manuais, como crochê, patchwork e bordados, foram analisadas, bem como as habilidades que gostariam de aprender, compartilhando os saberes com as colegas do projeto.

Como o projeto foi idealizado próximo ao verão, optou-se em projetar um acessório feminino para transporte e proteção de produtos básicos que comportam uma bolsa para praia, rio ou piscina. Na perspectiva, uma problemática foi abordada: alguns modelos não protegem porque são confeccionados com materiais que molham e sujam os itens que são levados.

Objetivando-se projetar uma bolsa funcional e que proteja os produtos, como toalhas e protetor solar, foi trabalhada em sala a possibilidade de desenvolvimento de produtos cuja matéria-prima principal fosse banners descartados pela UNIVILLE. Pretendeu-se, por meio de tal escolha, amenizar o impacto causado pelo descarte desses materiais utilizados como alternativas de comunicação e divulgação das ações sustentáveis da instituição, servindo como incentivo para o desenvolvimento de consciência ambiental.

Voltado ao projeto de um produto para o público feminino que aprecia o lazer junto à água para diminuir o calor dos dias quentes do verão e anseia por produtos ambientalmente amigáveis e que transmitam esse zelo por meio de um artefato confeccionado artesanalmente, foram desenvolvidas bolsas para a praia ou piscina. A base da bolsa agracia o tecido no tom cru, remetendo à natureza; forro confeccionado com lona de banner para o reforço e cuidado dos 
pertences no transporte e acondicionamento dos objetos; alças reaproveitando-se os bastões de madeira e ponteiras plásticas; cordão de náilon usado como porta-chaves e que seria desprezado. As bolsas foram customizadas artesanalmente com o crochê e patchcolagem, inspiradas no título "Cidade das Flores", como é conhecida a cidade de Joinville.

Figura 1 - Bolsas para praia ou piscina confeccionadas pelas integrantes do projeto SempreViva em 2014.

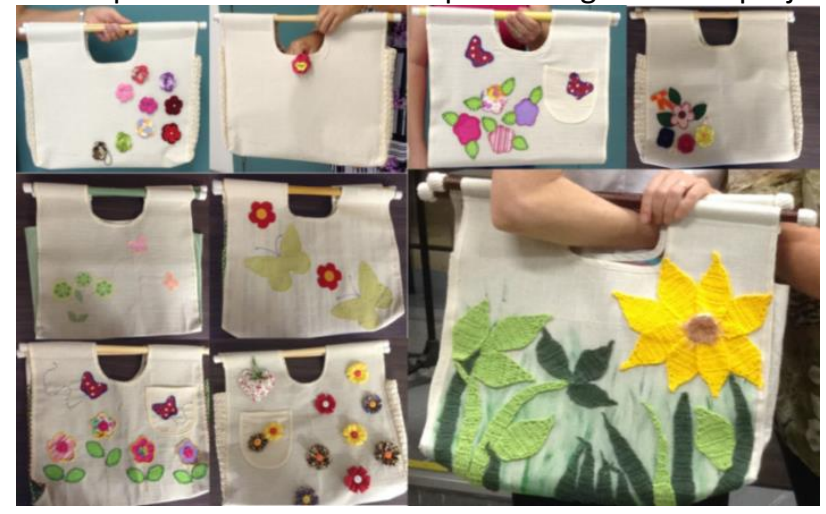

Fonte: Primária (2014).

É interessante observar que, mesmo com o emprego de maquinário industrial, algumas participantes optaram em costurar as laterais das bolsas à mão, por meio do ponto caseado. Outras perceberam que as ponteiras plásticas não condiziam com a caracterização da bolsa personalizada, preferindo-se fios ou tecidos para o acabamento.

\subsubsection{Desdobramentos e resultados junto ao Projeto Vida em Flor}

Com base nas reflexões da pesquisa, deu-se início a uma nova proposta no que diz respeito a ações para a valorização local. Assim, o projeto Vida em Flor desenvolveu nas dependências da UNIVILLE oficinas com mulheres oriundas do bairro Ulysses Guimarães (população: 9.418 Estimativa Ippuj, 201046), Loteamento José Loureiro (local invadido e próximo ao mangue) de Joinville. Por meio das atividades proporcionadas aos integrantes, com foco em modelagem e costura, os agentes produtores tiveram acesso a conhecimentos técnicos e estéticos em projeto de produto, projeto de programação visual e estamparia.

Preliminarmente, incentivou-se em sala de aula que os integrantes falassem sobre o local em que moram. Foram montados mapas mentais com as principais características do bairro e quais técnicas artesanais eram de conhecimento ou domínio do grupo. No intuito de valorizar o bairro, foram realizadas oficinas de projeto de programação visual no local onde residem, distante cerca de $7 \mathrm{~km}$ do centro da cidade. Primeiramente os integrantes foram instigados a conhecer o ambiente onde moram. Mais precisamente, a olhar de maneira diferenciada e observar a importância da preservação de uma área tão próxima ao mangue. Numa primeira pesquisa de campo, feita pelos professores, estagiários e integrantes do projeto, fotografaram-se a fauna e flora do bairro, margeados pelo Rio Velho, braço da Baía da Babitonga.

Em seguida, as integrantes puderam trocar informações e experiências acerca do local onde vivem. Num primeiro momento, com material visual, puderam conhecer a geografia e história do bairro. Chamou a atenção o fato de $90 \%$ dos integrantes não saberem quem foi o político e advogado agraciado com o nome do bairro (Ulysses Guimarães). Em seguida, sobre a

\footnotetext{
${ }^{46}$ IPPUJ: Instituto de Pesquisa e Planejamento Urbano de Joinville. web, 2014.
} 
população do bairro ser jovem, com cerca de 50\% (Censo IBGE 2010) com idade de até 24 anos. E por último, o quanto o local onde habitam é envolvido por manguezais que abrigam rica representação da fauna e flora de nossa região.

Com o encerramento do segundo semestre das atividades do projeto Vida em Flor, com remanescentes e novos integrantes do Loteamento Jardim Loureiro foram realizadas novas oficinas com foco na modelagem e costura. Confeccionaram-se novas peças de vestuário, com inspiração na cidade de Joinville (FIGURA 2). Como percebido no 2 ㅇ semestre do ano anterior ${ }^{47}$, os participantes poucos sabiam sobre Joinville. Nas oficinas, conheceram a história, geografia e infraestrutura do município, por meio de vídeos e fotografias. Em seguida, foram instruídos na busca de ilustrações que retratassem Joinville.

O projeto Vida em Flor investiu no desenvolvimento de vestuário representativo dos elementos visuais locais (linhas, formas, cores e texturas). Em sua execução, saberes relativos ao campo do design de moda (modelagem, costura e estamparia) evidenciaram o desenvolvimento amigável do processo produtivo, investindo na aplicação de tintas naturais, extraídas de vegetais encontrados pelos integrantes no próprio bairro, e priorizando a valorização dos produtos por meio de aplicação de técnicas artesanais manuais, nas "sobras" de tecidos retiradas no corte da peça do vestuário.

O projeto de produto foi direcionado ao público jovem, feminino, altamente presente no bairro. Foram desenvolvidas bermudas e camisetas. A base das bermudas contempla os tons de verde e azul, encontrados na vegetação, rios e canoas de pescadores. As peças foram customizadas, pois cada integrante optou por técnicas ancoradas em habilidades manuais individuais, como fuxico, macramê e patchcolagem. A técnica de macramê (representativa das redes de pesca) foi obtida por meio do tingimento natural do açafrão. As flores de fuxico e canoa de patchcolagem foram confeccionadas a partir das sobras dos tecidos tingidos com açafrão e urucum. Os detalhes dos miolos dos fuxicos, da rede de pesca e vela da canoa foram adornados com sementes naturais de açaí.

Figura 2 - Bermudas customizadas ancoradas em habilidades manuais individuais de cada integrante,

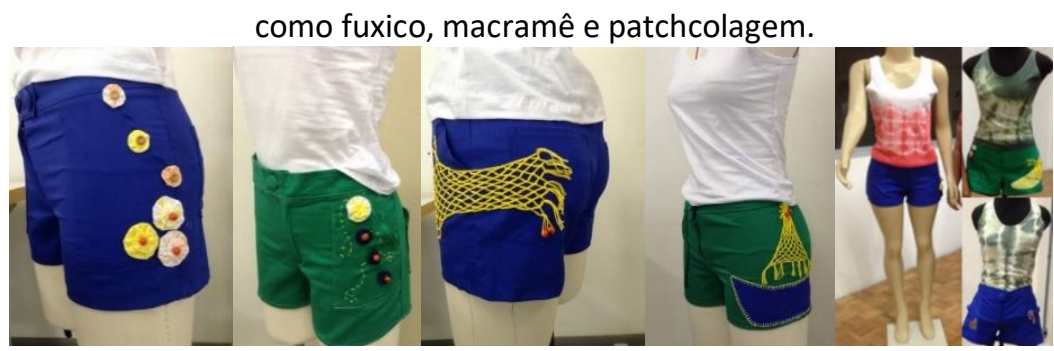

Fonte: Primária (2013).

Na personalização das bermudas, chamou a atenção a confecção da rede. Na oficina ministrada pela bolsista Daiane Fontana, puderam aprender e conhecer uma nova maneira de confeccionar a rede para enfeite das peças. Nela, a estudante destacou que aprendeu essa habilidade (desmanche de toalhas de algodão para utilização dos fios) com sua avó e acrescentou que viaja nas férias para aprender novos conhecimentos a respeito do fazer manual. Nota-se então quão valioso é o aprendizado com os mais velhos, especialmente para estudantes de moda que conseguem enxergar a importância das técnicas artesanais nos produtos contemporâneos.

Apoiando-se na análise de uma experiência prática com integrantes procedentes do bairro

\footnotetext{
${ }^{47}$ Pouco ou nada sabiam sobre o bairro que residem.
} 
Ulisses Guimarães, mais precisamente do loteamento José Loureiro, tendo como foco modelagem e costura, promoveu-se o reconhecimento das ferramentas do design de moda, de forma participativa, de modo a buscar valorização do território, transmitida por meio da confecção de peças do vestuário que representem características do local onde residem.

Bourdieu ${ }^{48}$ reitera que os habitus propiciam as diferenças nas práticas dos agentes, ou de seus grupos, em meio ao campo. Desse modo, percebeu-se no estudo que, em Joinville, a herança cultural marcada pelo hibridismo cultural é acentuada, já que a cidade comporta pessoas provenientes de outras localidades, estimuladas pela característica industrial e universitária do município. Dessa forma, como bem esclarece Bourdieu, constatou-se que que não basta analisar o objeto de estudo, isoladamente, faz-se necessário considerar o campo no qual o agente está incluído e o sistema simbólico nele estabelecido.

Assim, observaram-se os benefícios propiciados mediante o conhecimento teórico e prático acerca do bairro e da cidade em que os agentes estão inseridos. Procurou-se, por meio das ferramentas do design de moda, a valorização da localidade, representada na confecção de artefatos que carregam características presentes do local onde residem.

Constata-se que, a partir da aplicação das ações fundadas na teoria do design participativo, as integrantes passaram a reconhecer a sua identidade e começaram a ter um novo olhar sobre a sua realidade. Considera-se que deverá ser "ela própria", conforme atividades dos projetos, a protagonista responsável pelo desenvolvimento local, de forma participativa e comprometida com os recursos naturais presentes no município. Nota-se que com as ferramentas apropriadas as pessoas se unem, são criativas, se manifestam e participam do processo de design, levando à colaboração e à inovação, buscando-se a adaptação da cultura do agente ao novo ambiente.

\section{Considerações finais}

O artigo relata os desdobramentos e principais resultados da investigação "Design e Artesanato: uma relação social recíproca" desenvolvida junto ao Mestrado Profissional em Design da Universidade da Região de Joinville. A investigação objetivou verificar a contribuição dos estudos fundados na abordagem social, para o campo do Design de Moda, visando aplicabilidade junto a projetos que visam geração de trabalho e renda, por meio de processos artesanais. O estudo identificou e analisou potencialidades de colaboração entre professores e estudantes e grupos femininos, integrantes de projetos de extensão universitária, primando pela integração de ferramentas e tecnologias acadêmicas com conhecimentos populares de técnicas, processos e materiais locais.

O desenvolvimento da pesquisa, apoiada na teoria dos sistemas simbólicos de Pierre Bourdieu, destacou a relevância de estabelecer-se uma relação social recíproca, marcada pelo hibridismo cultural, entre designers e artesãos. Investindo na conceituação do campo do Design de Moda, pelo viés sociológico, contextualizou as práticas de designers de moda e destacou o caráter multicultural de Joinville e Região. Nesse processo, enfatizou a produção cultural e mercado local da cidade de Joinville, onde os agentes produtores estão inseridos.

Propôs-se uma aplicação da teoria na prática, no intuito de obter-se um senso prático e não meramente teórico. A pesquisa prática, relatada foi aplicada junto a dois grupos específicos: Projeto de Renda 'Vida em Flor' e Geração de Renda: Grupo 'SempreViva'. Esses grupos foram selecionados por constituírem-se de integrantes do primeiro ano de capacitação e, assim, sem

\footnotetext{
${ }^{48}$ BOURDIEU, 2013.
} 
vícios metodológicos. Os referidos grupos reúnem-se semanalmente nas dependências da UNIVILLE, com carga de quatro horas semanais, sendo orientados por professores dos cursos de design e Administração, e apoiados por estudantes bolsistas e voluntários.

Concebendo os saberes cultos do Design e os saberes populares do artesanato, em meio a uma relação social recíproca, marcada pelo hibridismo cultural, e tendo como pano de fundo a teoria dos sistemas simbólicos, desenvolvida por Pierre Bourdieu, propôs-se uma análise das práticas dos grupos integrantes dos projetos que visam geração de trabalho e renda, desenvolvidos pela Extensão Universitária da UNIVILLE. Nesta abordagem prática, os referenciais teóricos foram confrontados com a pesquisa prática, sistemática, que objetivou romper com o senso comum ao estabelecer relações do objeto estudado com fatores externos (históricos, sociais, culturais, filosóficos, econômicos). A pesquisa prática foi realizada e registrada com apoio com apoio de fichas cadastrais dos projetos, registros imagéticos e inserções (da pesquisadora) para planejamento, práticas e discussões em grupo.

As reflexões apresentadas, adentraram nas questões estruturais e técnicas (as oficinas; os materiais) aplicadas ao longo dos anos de existência dos projetos; na sequência, confronta-se a teoria de apoio desta investigação, com as referidas práticas dos grupos femininos (os projetos definidores das práticas), ultrapassando-se as metodológicas, comumente disseminadas nos cursos de design, consideraram-se os agentes produtores, sua história e sua cultura. Apostou-se numa relação social recíproca entre Designer de Moda e artesãos. Ou seja, não uma relação de dominação simbólica ou econômica, mas uma prática que, situada histórica e socialmente, confere devido valor a artesãos e designers e promove o desenvolvimento sustentável, por meio de consideração ao meio ambiente na definição de técnicas, manejos e materiais elegidos.

A aproximação dos estudantes com os projetos ocasionou reconhecerem-se, na prática artesanal, novos saberes a respeito de técnicas utilizadas para a confecção e artefatos, acessórios e vestimentas, de maneira amigável diante do processo produtivo, na intensão de utilizar-se refugos de tecidos e tintas naturais, extraídas da vegetação encontradas pelos próprios integrantes. A partir do trabalho colaborativo, com a troca de conhecimento e informações entre bolsistas, professores, colaboradores e integrantes dos projetos propôs-se um olhar diferenciado aos futuros profissionais da área de design, vindo ao encontro dos valores e princípios da Extensão universitária da UNIVILLE: possibilitar o aprendizado ultrapassando os espaços acadêmicos, aproximando o conhecimento científico e o conhecimento popular.

\section{Referências}

BOURDIEU, Pierre. A distinção crítica social do julgamento. Porto Alegre: Zouk, 2008.

A economia das trocas simbólicas. São Paulo: Perspectiva, 2007.

A economia das trocas simbólicas. São Paulo: Perspectiva, 2011.

A produção da crença. Zouk, 2006.

O amor pela arte. São Paulo: EDUSP, 2007.

O poder simbólico. Rio de Janeiro: Bertrand Brasil, 2002.

O senso prático. Petrópolis: Vozes, 2013.

. Razões práticas sobre a teoria da ação. São Paulo: Papirus, 2003. 
CANCLINI, Néstor García. Culturas híbridas: estratégias para entrar e sair da modernidade. 4. ed. São Paulo: EDUSP, 2011.

Culturas híbridas. 4. ed. São Paulo: EDUSP, 2013.

Sociedade sem relato: antropologia e estética da iminência. São Paulo: EDUSP, 2012.

SCARTEZINI, Natália. Introdução ao método de Pierre Bourdieu. Artigo UNESP. São Paulo: [s.d.].

\section{Complementares:}

BURKE, Peter. Hibridismo cultural. São Leopoldo: Ed. UNISINOS, 2003.

CIPINIUK, Alberto. Design e artesanato: aproximações, métodos e justificativas. In: CONGRESSO BRASILEIRO DE PESQUISA E DESENVOLVIMENTO EM DESIGN, 7., 2006, Paraná. Anais...

Design: o livro dos porquês - o campo do design compreendido como produção social. Rio de Janeiro: Reflexão, 2014.

; PORTINARI, Denise B. In: COELHO, Luiz Antonio L. Design método. Rio de Janeiro: PUCRio; Teresólis: Novas Idéias, 2006.

FURJ - FUNDAÇÃO EDUCACIONAL DA REGIÃO DE JOINVILLE. Disponível em: <http://novo.univille.edu.br/null/pt-BR/a-univille/fundacao/605894>. Acesso em: 31 ago. 2014.

IPPUJ - INSTITUTO DE PESQUISA E PLANEJAMENTO URBANO DE JOINVILLE. Disponível em: <ippj.joinville.sc.gov.br>. Acesso em: 28 mar. 2014.

JOINVILLE: 150 anos. Joinville: Letradágua, 2001.

JOINVILLE em dados. EDM Logos Comunicação, 2013.

LINKE, Paula Piva; VELHO, Ana Paula M. Moda, artesanato e cultura. Revista Multidisciplinar da UNIESP, 2014.

MORGENSTERN, Elenir Carmen; CIPINIUK, Alberto. Arte e design, fronteiras evanescentes? 2011. 190 f. Tese (Doutorado)-Pontifícia Universidade Católica do Rio de Janeiro, Rio de Janeiro, 2011.

RECH, Sandra R.; SOUZA, Renata K. R. Ecoluxo e sustentabilidade: um novo comportamento do consumidor. Disponível em: <http://futurodopresente.ceart.udesc.br/Site\%20Antigo/httpdocs/Artigos/Sandra\%20Rech_Renat a\%20de\%20Souza_Futuro\%20dd\%20PresenPr_Relatorio\%20Final.pdf>. Acesso em: 5 jun. 2014.

SILVA, Janine Gomes da. Tensões, trabalhos e sociabilidades: histórias de mulheres em Joinville no século XIX. Joinville: Univille, 2004.

SOUZA, Júlia Brümmer. O design de moda e a instituição social da cultura simbólica. Caderno de Iniciação à Pesquisa, Joinville, 2014.

THIRY-CHERQUES, Hermano Roberto. Pierre Bourdieu: a teoria na prática. Rio de Janeiro, 2006.

UNIVILLE - UNIVERSIDADE DA REGIÃO DE JOINVILLE. Área de Extensão Universitária. Disponível em: <http:// novo.univille.edu.br/pt-BR/a-univille/proreitorias/proex/areaextensao/index/597362>. Acesso em: 24 set. 2014.

VEGINI, Valdir. Subsídios para o plano de desenvolvimento institucional da UNIVILLE. Joinville: UNIVILLE, 2004. 